\section{$7 \quad$ Reid and the Social Operations of Mind}

\section{INTRODUCTION}

Thomas Reid is justly famous for his critique of the metaphysics, epistemology, and psychology of his influential predecessors and overlapping contemporaries. Debate continues about the success of his critique, but the philosophical intelligence displayed in his dissection of the faults in "the way of ideas" common to such otherwise disparate thinkers as Descartes, Locke, and Hume is beyond doubt. Indeed, Reid's critique is an exemplary piece of philosophical art in that it aims to detect a central flaw in the underpinnings of a great enterprise. It exhibits the "subtle but well balanced intellect" that was later praised by C. S. Peirce. ${ }^{\text {I }}$ But this very achievement has tended to obscure some of Reid's more positive contributions to philosophy. Of course, his defense of common sense and his elaboration of what it means have been subject to plenty of critical attention, but there are many other areas in which Reid developed creative and original positions that have been relatively neglected in the literature. In what follows, I shall expound and discuss one that has been largely ignored both in its general form and in its particular applications.

The idea in question is that of "the social operations of mind." Reid develops this idea both in his Inquiry and in the Essays and deploys it in his discussion of a number of important topics, most notably those of promising and testimony.

\section{HUME, REID, AND PROMISING}

I will begin the exploration of this concept of social operations with a dispute between David Hume and Thomas Reid over promising, contracting, and justice. Their disagreement is in any case interesting in its own right and displays some of Reid's characteristic modes of thought. Hume professes to find a sort of paradox or contradiction in a promise, and this is connected with his analysis of justice as an "artificial virtue." Although Hume rejects the social contract tradition in his famous essay "Of the Original Contract" and elsewhere, his analysis of justice has distinct affinities with it. He makes, for instance, considerable use of the device of a state of nature to explain the origin of justice, though he thinks it a useful "philosophical fiction" rather than an ancient state of affairs.

Similarly, although Hume is a critic of the outlook of psychological egoism, and raises objections to the idea that human motives are always egoistic, he founds his account of justice upon an essentially self-interested basis, in the sense that repaying debts, keeping promises, and acting fairly are justified by the interest each of us is said to have in the existence of the sort of social order where people generally conform to these norms. Justice is conventional in so far as we have contrived an order that promotes a public interest through the expectation each has that his or her private interest will generally be furthered by conforming to its demands. Our natural affections and passions would not drive us to just conduct, because, at their best, they are too limited; but our interest in maintaining the convention helps us develop an artificial sentiment for justice that underpins our honesty. For Hume, justice is primarily concerned with the regulation of property relations, though it spills over into other matters. It is an underlying premise of his "construction" of justice that it is a virtue necessitated by scarcity of goods, limited benevolence, and rough equality of power between people.

Hume's theory is developed with considerable sophistication, but it is exposed to the same problem that bedeviled Hobbes before him. It is the problem posed by the free (or "foul") rider whom Hobbes calls "the fool" in deference to the Biblical characterization of the atheist ("the fool has said in his heart, there is no God"). The parties to the justice convention have a lot at stake in the convention's being maintained and this should make them very cautious about defecting. But surely a cunning rogue can exploit circumstances in which his injustice is virtually undetectable, and, even if it is detected, the convention will stand and he may have ways of avoiding the bad consequences for himself. On the other side, there may, as 
Hume admits, be circumstances in which particular adherence to justice hardly seems to serve either the public interest or an individual's private interest: You have borrowed a small sum of money from an immensely wealthy person and can only repay it at considerable inconvenience, but justice requires that you do so even though the original lender has no serious need of the money and may even have forgotten the loan entirely. ${ }^{2}$

Hume faces this predicament partly because he has a particular sort of moral psychology - it is an axiom of his theorizing about morals that the motives for a moral action must always be them. selves independent of morality. Hence in the case where there is no "natural" motive for some category of moral behavior, its motivation must be sought in the desire to conform to convention and this desire in turn must be founded on the natural motive supporting the convention. With justice (and the contracting and promising that fall under it) this natural motive is ultimately self-interest or self-love. Justice is an artificial or contrived virtue that serves our self-interest by its promotion of the sort of stability and benefit that we could not have in a state of nature. By contrast, generosity is a natural virtue in that we are moved to it by certain natural motives, such as sympathy. Of course, there are various obscurities around the word "natural" as Hume himself realized (see below) and Hume wants to insist that justice may be called natural in the sense that using reason to arrive at a convention to promote advantage is a natural thing to do. Nonetheless, justice does not rest directly on natural impulse as generosity does.

Similar reasoning applies to the obligations involved in promising. Indeed, viewed as a natural phenomenon, promising itself becomes something mysterious and even contradictory. As Hume puts it: "A promise therefore is naturally something altogether unintelligible, nor is there any act of the mind belonging to it." 3 What Hume seems to mean, here, is that the obligation to perform that is inherent in promising cannot arise from merely saying that you will perform, from simply uttering the words. The obligation must arise from some natural motive associated with promising, but what could this be? It cannot be the "act of mind" of intending to perform, because you are obliged whether you intend to perform or not. The obligation involved in promising must therefore be the creation of artifice, and since contracting is simply a form of promising in which several people commit themselves to act on the condition that others act in specified ways, the same is true of it.

And, again, the fundamental backing for the obligation of promising is that of a contrivance to promote and protect self-interest. This is a fundamental philosophical reason, quite apart from sociological or historical objections, why Hume must oppose one central element in the social contract tradition: That tradition appears to establish social morality and justice on the prior "natural" obligation to keep promises whereas Hume regards this obligation as conventionally established. To quote Hume again: "But as there is naturally no inclination to observe promises, distinct from a sense of their obligation; it follows that fidelity is no natural virtue, and that promises have no force, antecedent to human conventions." 4 And again, "interest is the first obligation to the performance of promises. Afterwards a sentiment of morals concurs with interest, and becomes a new obligation on mankind. This sentiment of morality, the performance of promises, arises from the same principles as that in the abstinence from the property of others." 5

I shall not pursue the question whether, in dealing with "the fool," Hume's conventional theory of justice built upon a subjectivist theory of morality fares any better than Hobbes's social contract theory built upon a narrow version of natural law. What I will pursue is a response that Thomas Reid makes to Hume's moral psychology and, in particular, to his claim that there is no act of mind that naturally belongs to promising. Here Reid has direct recourse to his distinction between the solitary and social acts of mind, thereby challenging Hume's thinking not merely by objecting to his theory's inability to account for the moral realities (though Reid does that too) but by exposing something deeply wrong with its underpinnings. Indeed, Reid thinks that not only Hume, but many philosophers writing on social and political theory have failed to distinguish between the solitary and social operations of mind. They have treated the social operations as if they are merely versions of the solitary or reducible to them without loss.

\section{EXPLAINING THE SOCIAL OPERATIONS}

What is Reid's purpose in distinguishing between solitary and social operations of the mind? His idea is that there is a fundamental 
difference between the operations of the mind that require no reference to other intelligent beings and those that do. The social operations or acts of mind are essentially geared to "intercourse with some other intelligent beings" (EAP V.vi: 664a), whereas the solitary operations are not. Solitary operations are seeing, hearing, remembering, judging and reasoning, forming purposes and executing them. None of these require "the intervention of any other intelligent being" (ibid.). By contrast, asking questions, testifying, commanding, making a promise, or entering into a contract are social acts that "can have no existence without the intervention of some other intelligent being, who acts a part in them" (ibid.). Reid adds that the social operations are essentially geared to expression whereas the solitary operations are not. Reid thinks of expression as intrinsically oriented toward communication and as requiring symbolic form. It is at least conceivable that a person without some form of language might think, reason, deliberate and will, have desires and aversions, experience joy and sorrow, but it would be impossible for such a being to "put a question, or give a command, to ask a favour, or testify a fact, to make a promise or a bargain" (ibid.). Nonetheless, as we shall see, Reid does not think that "artificial" languages, including those of ten called natural languages to distinguish them from formal symbolic systems, are the only form that language can take.

The powers upon which the social operations rest may well be innate. Reid sometimes appears to leave this an open question, though many of his comments make it seem that the powers are part of our constitution. In any case they are clearly universally present in human beings, though their operation is weaker in infancy. Reid thinks that the social operations initially rest upon what he calls a "natural language" of signs, such as looks, gestures, and modulations of the voice, without which artificial languages would be impossible. These signs make for a communicative and receptive orientation among people that underpins the obligations, duties, and moral expectations involved in promising and other social operations. ${ }^{6}$ Contrary to Hume, promising - like entreating, questioning, and commanding is therefore a perfectly natural phenomenon and there is no need to seek its morality in some contrivance or convention designed to promote public and private interest. It is clearly Reid's view that promising, though no doubt of a very simple kind, may be expressed in the natural language, just as much as entreaties and warnings.
Reid's emphasis on the social operations has understandably been compared by some commentators to J. L. Austin's discovery of "performative utterances" and the subsequent development of speech act theory. ${ }^{7}$ One point of similarity is Reid's insistence that the social operations are precisely social and actions. Another is the idea that an act of promising, for example, is constituted by a certain sort of expression, namely, one uttered with an understanding and "a will to engage" (EAP V.vi: 670a). There is a third resemblance in that Reid seems to recognize the need for some condition of "uptake" (as Austin called it) if a social operation is to be adequately performed ("felicitous" in Austin's terminology). This is a condition on the audience, though it implies a responsibility in the speaker, that, minimally, the utterance be understood for what it is. In the case of promising, moreover, the act is not adequately performed unless the one to whom the promise is offered accepts it. The flavor of Reid's account and parallels with Austin can be glimpsed in such remarks as the following: "such is the nature of all social acts of the mind, that, as they cannot be, without being expressed, so they cannot be expressed knowingly and willingly, but they must be" (ibid.). And again: "What makes a promise is, that it be expressed to the other party with understanding, and with an intention to become bound, and that it be accepted by him" (EAP V.vii: 669b).

Yet another parallel with Austin's work can be seen in Reid's interest in the degree to which an account of these neglected social operations is ill-served by the (then) standard logicians' treatment of discourse as the expression of propositions assessable straightforwardly as true or false. Beginning with those performatives that are not plainly assessable as true or false (e.g., commands or questions) Austin, in his early treatment of performative utterances, was inclined to make much of performatives not being "descriptive" and therefore not in the business of being true or false, though later he realized that the story was more complex. Reid also seems drawn to this temptation and, although he resists its full force, he is led partly by it to some strange comments, especially about testimony, which he thinks cannot erroneously express judgment, though it can be deceitful: As I have argued elsewhere and will emphasize in the discussion of testimony to follow below, this halfway house is unsatisfactory, but Reid reaches this pass because of his view that the social operations do not express "judgments." Again, we shall examine 
this further when we discuss testimony since the view raises more obvious problems with such social operations as testimony and warning than with promising or commanding. For now, it is sufficient to note that Reid is here pioneering an approach to speech act theory that would become more judicious and sophisticated later, even though much still remains unsettled on these topics. ${ }^{8}$

Reid, like Austin after him, is anxious that the social operations not be misconstrued as created by private (solitary) mental acts. 9 But he is also clear that they are themselves mental in a broader way, which is why he distinguishes the solitary from the social operations of mind. Consistent with this, Reid castigates Hume both for denying that there is any act of mind constitutively belonging to promising and for constantly construing the mental element in promising as the intention (or purpose) of performing what one has said one would. Hume generates his supposed contradiction partly by insisting that no mere intention could have the force that promising clearly does, and by insisting at the same time that the intention to perform as indicated is crucial. But, as Reid points out, this intention may or may not be present; the crucial, constitutive mental element is not the solitary act of intending to perform, but the social mental act of intentionally binding oneself to perform. ${ }^{\text {I }}$

\section{SOME CONSEQUENCES OF REID'S POSITION}

Reid's perspective on justice, promising, and contract allows us to afford appropriate respect to contractual and other justice-related notions by situating them within an understanding of human life and interaction which takes our life in community as fundamental, but is not foolishly sentimental about it. Reid holds that the treatment of justice (and promising) as artificial, in Hume's sense, flies in the face of elementary moral experience. He sees our natural tendency to fidelity in declarations and promises and its counterpart in the widespread trust and reliance upon them as fundamental to our life as social beings. ${ }^{\text {II }}$

There is a discussion of Hume's that illustrates nicely, I think, the advantages of Reid's approach. In An Enquiry concerning the Principles of Morals, Hume has a revealing account of what our obligations would be to a class of people who lived among us but who were so weak as to constitute no threat to us were we to treat them in ways they resented. Here is what he says:

Were there a species of creatures, intermingled with men, which, though rational, were possessed of such inferior strength, both of body and mind, that they were incapable of all resistance, and could never, upon the highest provocation, make us feel the effects of their resentment; the necessary consequence, I think, is that we should be bound, by the laws of humanity, to give gentle usage to these creatures, but should not, properly speaking, lie under any restraint of justice with regard to them, nor could they possess any right or property, exclusive of such arbitrary lords. Our intercourse with them could not be called society, which supposes a degree of equality but absolute command on the one side, and servile obedience on the other. Whatever we covet, they must instantly resign: Our permission is the only tenure, by which they hold their possessions: Our compassion and kindness the only check, by which they curb our lawless will: And as no inconvenience ever results from the exercise of a power, so firmly established in nature, the restraints of justice and property, being totally useless, would never have place in so unequal a confederacy. ${ }^{12}$

Some may be tempted to think that this accurately describes the position of women in a male-dominated society, and Hume indeed shows the courage of his convictions by going some way towards drawing this conclusion. In the next paragraph, he tests the idea on animals, Indians, and women, claiming that it is "plainly" the situation with regard to animals (supposing them to have some degree of reason) and that "civilized" Europeans have been tempted to see themselves in the same relation to "barbarous" Indians and so thrown off all restraints of justice and even humanity in regard to them. As for women, let me quote Hume in full:

In many nations, the female sex are reduced to like slavery, and are rendered incapable of all property, in opposition to their lordly masters. But though the males, when united, have, in all countries, bodily force sufficient to maintain this severe tyranny, yet such are the insinuation, address, and charms of their fair companions, that women are commonly able to break the confederacy, and share with the other sex in all the rights and privileges of society. ${ }^{13}$

The full import of this passage is not altogether clear, but it seems that if women are spared the fate of animals and admitted to the confederacy of justice, it is only because of their insinuating charm. 
It would not be surprising for feminists to jib at this remarkable conclusion. And not only modern feminists. As Reid remarks, "If $\mathbf{M r}$ Hume had not owned this sentiment as a consequence of his Theory of Morals, I should have thought it very uncharitable to impute it to him" (EAP V.v: 66ob). By contrast, Reid grounds justice and its offspring (the obligations of promising and contracting) in those social operations that are based upon a fundamental mutuality of kind rather than equality of power. ${ }^{14}$

Reid's theory certainly avoids such counterintuitive land offensive) conclusions, since the subjects to whom the rights and duties of justice are relevant are not determined by exigencies of power, scarcity, and so forth, but by profound relations of sociality that are "natural." Of course, it may be objected that not a great deal is achieved by calling something "natural" and contrasting it with "artificial." Hume himself was conscious of much that is problematic about the distinction, and went to some lengths to distance himself from any connotations of "conventional" or "artificial" that suggested something unimportant or simply arbitrary about the emergence of justice as a virtue or institution. In the Treatise, he says: "Tho' the rules of justice be artificial, they are not arbitrary." 's And in An Enquiry concerning the Principles of Morals, he comments: "The word natural is commonly taken in so many senses and is of so loose a signification, that it seems vain to dispute whether justice be natural or not. If self-love, if benevolence, be natural to man; if reason and forethought be also natural; then may the same epithet be applied to justice, order, fidelity, property, society." ${ }^{16}$

There are indeed many obscurities about contrasts between the natural and the conventional or artificial, whether the distinction is deployed in connection with rights or virtues, tendencies or abilities. It is also clear that Hume does not want to underplay the importance of justice as a virtue and a phenomenon. But the basic contrast that Hume needs is contained in his quoted response, and it still puts him at odds with Reid, and with others, like Aristotle and many contemporary feminists and communitarians, who want to see human beings as essentially social. For them, justice does not arise from mutual reasoning about what is advantageous to self-interest and promotional of social utility; it is inherent in the interactive social realities of human nature.

\section{THE ROLES OF THE SOCIAL AFFECTIONS}

The social operations to which Reid is attentive are allied to what he calls "social affections" and should remind us that there are certain fundamental human reactions intimately connected with the idea of justice that pre-date (so to speak) the prospect of any contrivance of the kind Hume imagines as establishing the virtue. Such reactions were emphasized by P. F. Strawson years ago in his important paper, "Freedom and Resentment"17 but were also stressed by Reid in the context of his disagreement with Hume. (They have also been reconsidered by Joan McGregor, who cites Strawson's account in a good discussion of some aspects of Reid's views on justice as a natural virtue. $\left.\right|^{18}$ As Reid puts it: "man is evidently made for living in society. His social affections show this as evidently, as that the eye was made for seeing. His social operations, particularly those of testifying and promising, make it no less evident" (EAP V.vi: 666a). And again: "Every man thinks himself injured and ill used, and feels resentment, when he is imposed upon by it.... I know of no evidence that has been given of any nation so rude, as not to have these sentiments" (EAP V.vi: 666b).

These "reactive attitudes," as Strawson calls them, such attitudes as resentment, indignation, and gratitude, are basic to reflective humans and already embody a moral perspective. They require some development of the reasoning faculty, though there are premonitions of them in animals and very young children. ${ }^{19}$ As Reid puts it, "I take it for granted that gratitude and resentment are no less natural to the human mind than hunger and thirst; and that those affections are no less naturally excited by their proper objects and occasions than these appetites" (EAP V.v: 654b). The proper object of resentment is an injury, and not merely a hurt, and this involves the idea of justice directly; the object of gratitude is a favor done and this involves the idea of justice indirectly in so far as one must go benevolently beyond the demands of justice in order to do someone a favor. Nor should we think that resentment, at any rate, must be an attitude to an injury done to oneself; we can resent wrongs inflicted on others, especially if the wrongs are great and we can readily have fellowfeeling for those others. A mother can resent the treatment of her child, and I can resent the wrongs inflicted on others by those who purport to act in my name. There seems no incoherence in my saying 
sincerely, "I deeply resent the Australian government's appalling treatment of refugee boat people landing on our shores." Similarly a parent can be grateful for favors bestowed on his child, though gratitude does not seem to extend coherently to favors bestowed on those not intimately connected to oneself. In any case, the picture Reid presents of the connection between human nature and justice is far removed from the self-interest model. As he says himself, he rejects the various attempts "to reduce all our social affections to certain modifications of self-love" (EIP I.viii: 69).

\section{PROBLEMS FOR THE SOCIAL OPERATIONS OF MIND}

None of this is intended to suggest that Reid's ingenious idea of the social operations of mind is without problems. One question that needs addressing is this: In what sense are the social operations "mental"? If we are in the grip of a Cartesian picture of the mind, we will find it strange to speak of such overt public acts as promising or testifying as acts of mind at all. Even adherents of certain popular forms of materialism who treat the mind as a particular physical rather than nonphysical thing, to wit, the brain, will have similar qualms since the interactions involved in testifying or promising seem far from the merely neural. Indeed, there are certain respects in which theories such as central-state materialism simply take over the Cartesian picture of the mind but hold that the stuff of the substantial mind is physical rather than spiritual thereby propounding what the philosopher William Ginnane once aptly called "one-legged dualism." Of course, the social operations involve the mind (and/or brain) in so far as agents need to be mindful to perform them, but Reid seems to mean something richer than this.

If so, he doesn't really elaborate on what it is. As we saw earlier, he thinks the social operations are essentially oriented to "intercourse with other intelligent beings" whereas the solitary operations such as seeing, hearing, remembering, and reasoning are not. These latter do not require "the intervention of any other intelligent being." By contrast, asking questions, testifying, commanding, making a promise, and entering into a contract are social acts that "can have no existence without the intervention of some other intelligent being, who acts a part in them" (EAP V.vi: 664a). They are also essentially geared to communicative expression whereas the solitary operations are not.

These comments suggest that we should think of the mind in such a way that there are certain mental states (those involving social operations) that cannot exist without the existence and reciprocal orientation of other intelligent beings. This goes against the picture, associated with Descartes, that a person (or a soul) could have exactly the mental states she now has whether or not any other being (except possibly God) existed at all. Reid does not mount a direct attack upon this picture, and in many respects he accepts a good deal of Descartes' thought about the mind. On the other hand, his rejection of the way of ideas and his attempts to analyze perception in a fashion that is object-involving but also respects the role of sensation both suggest an approach to the mind that is initially not as introverted as that of Descartes.

I think it is not implausible to see Reid as foreshadowing some developments in recent philosophy of mind and semantics that pose a challenge to the Cartesian picture. This challenge is sometimes put in terms of the idea of wide mental content. The thesis of wide content argues that at least some mental states are necessarily connected with certain nonmental realities that they represent. Hence, were it not for the existence of that reality, they couldn't be the states they are. The reality may be either physical or social.

A simple example concerns proper names. On accounts of the semantics of proper names influenced by the work of Kripke on rigid designation, the meaning of a sentence such as "Cathy Freeman is in excellent form" involves essential reference to that actual athlete. Someone who has the thought involved in that sentence is, as it were, connected to Freeman by that very thought. This is not a connection that is fully mediated by any private descriptions of Freeman that the thinker has. There is already a sort of externality built into the mental state. More broadly, it has been argued that much of what makes particular thoughts and other psychological states what they are is contributed by the conceptual and linguistic expertise of others. Hilary Putnam has spoken of a "linguistic division of labor" whereby any individual's grasp of what an expression like "elm" or "neutron" means, for example, is partly a gift of others in the community more expert on these matters. Considerations like these lead Putnam to announce triumphantly that meanings "ain't in the head." 20 The 
picture of the mind as having a wholly individualistic grasp of the world from "within" is threatened by these considerations.

The theories of wide content have many ambiguities and complexities, and al though very influential, have not been without their critics. ${ }^{21}$ Nonetheless, this more expansive attitude to what counts as mental may make us more sympathetic to the way Reid seems to think of some of the workings of the mind as essentially social. But, of course, there are various differences between the contemporary perspectives and that adopted by Reid in speaking of the social operations of mind. For one thing, in the Cathy Freeman example, the "externality" involved is different in that the Australian athletic champion need know nothing of her involvement in my thought that she is in good form and so the "externality" is not social in the way Reid is concerned with sociality: It is not interactive. But in testifying and promising, it is not that (or only that) the mind reaches out to external objects in being dependent upon them for the identity of its thoughts; the mind involves certain types of those objects, namely, persons, in a mutual transaction requiring at least "uptake." Minimally, as mentioned earlier, this will mean an understanding of what is on offer, though it may require more in some cases. Promising, for instance, may need a certain sort of acceptance (as contracting clearly does). In other words, the kind of mutuality of mind involved will vary from category to category with the social operations.

Another complexity about the social operations is that Reid's presentation of them and their associated social affections may suggest that they are an unqualified boon. But Reid is well aware that the social operations are not uniformly benign, although this recognition tends to be relegated to the background of his discussion. Our sociality yields the flowers of promises and fidelity, but it also gives us the thorns of threats and collusion; it makes justice natural, but it also underpins corruption and conspiracy. Trust itself can degenerate into degrading dependence and gullibility; it can also provide the cement of evil enterprises (as Annette Baier acknowledges). Even the mother/child relationship may involve its own excesses, as a good deal of contemporary humor highlights.

Reid himself acknowledges the distorting power of our moral impulses in his account of resentment where he treats resentment under the heading of "the malevolent affections" and judges that its proper operation in connection with justice may easily sweep on to dangerous exaggerations of grievance and vengefulness. And much the same is true of the other malevolent emotion he discusses, namely, "emulation," which is his term for what we might call competitiveness. Of these, Reid writes: "But, as their excess or abuse, to which human nature is very prone, is the source and spring of all the malevolence that is to be found amongst men, it is on that account that I call them malevolent" (EAP III.ii.v: $566 \mathrm{~b}$ ). This tendency to excess or abuse is what the institutions of justice, such as courts, police, enacted laws, and regulations, are required to restrain and here there is plenty of room for artifice and contrivance. Justice may be natural to our kind, but the forms and institutions that it requires may need the constructions of reason built partly upon fear and partly on consent. These constructions need to acknowledge both our powerful natural tendencies to social virtue, preeminently justice and fidelity, and our very strong tendencies to selfishness and partiality (upon which both Hobbes and Hume place such emphasis.)

\section{THE CASE OF TESTIMONY}

We must turn now to another significant philosophical example of the social operations, this time in the area of epistemology, namely, the giving and receiving of testimony. Reid's placing of testimony within the social operations is part of his antireductionist attitude to the reliability and value of testimony. He sees the futility of attempting to justify the widespread and crucial dependence upon what others report by consulting only solitary intellectual resources. This resort to self-reliance is, Reid believes, as doomed as the parallel resort to self-love in the case of promising. Both ignore the primitive nature of our intellectual and practical involvement with others. Trust in the information given by others cannot sensibly be viewed merely as a useful strategy that an individual knower could and should develop on grounds of self-interest and with the aid of the self-reliant equipment of sense, memory, and inference. The quest for knowledge begins with dependence upon the word of others rather than validating that dependence some way down the path as a secondary supplement to individual knowledge. This "beginning" is historical and also epistemically normative.

Reid points out that a child's development is in fact dependent upon a primary attitude of trust, and, in these very early stages, the 
trust is virtually total. Were the child's attitude to the reliability of testimony one of indifference, or "in equilibrio" as Reid has it, then "no proposition that is uttered in discourse would be believed, until it was examined and tried by reason; and most men would be unable to find reasons for believing the thousandth part of what is told them" (IHM VI.xxiv: I94). Hence, the child's "credulity" seems no accident. Indeed, on the "in equilibrio" supposition, a child would (says Reid) be absolutely incapable of instruction. Here Reid seems to be supporting his view that reliance on testimony stems from a principle of human nature rather than from experience. Indeed he thinks that there are twin principles that act as "counterparts" - the principle of veracity and the principle of credulity. Reid characterizes the former as "a propensity to speak truth, and to use the signs of language so as to convey our real sentiments," and claims that: "Truth is always uppermost, and is the natural issue of the mind. It requires no art or training, no inducement or temptation, but only that we yield to a natural impulse" (IHM VI.xxiv: 193). The latter principle - the principle of credulity - is a disposition to, as Reid puts it, "confide in the veracity of others, and to believe what they tell us" (IHM VI.xxiv: 194). And this too Reid takes to be a natural disposition: "It is evident that, in the matter of testimony, the balance of human judgment is by nature inclined to the side of belief; and turns to that side of itself, when there is nothing put into the opposite scale" (ibid.).

Reid's argument from the child's development is then partly an elaboration of the force of the twin principles, but it also has something in common with arguments of a transcendental form. There are certain things we know and do that we couldn't know or do if reliance on testimony were justified by reasoning from experience. Yet, in what follows the comment on the child, he seems to allow that some people might come to accept the reliability of testimony by reasoning from experience. So he says, commenting on the "in equilibrio" supposition:

Children, on this supposition, would be absolutely incredulous; and therefore absolutely incapable of instruction: those who had little knowledge of human life, and of the manners and characters of men, would be in the next degree incredulous: and the most credulous men would be those of greatest experience, and of the deepest penetration; because, in many cases, they would be able to find good reasons for believing the testimony, which the weak and ignorant could not discover. (IHM VI.xxiv: 194-5)

This may be indicative of a certain tension in Reid's thought on the matter, though it is clear from what follows later that he does not envisage the operations of reason and experience entirely eliminating our reliance upon testimony. Shortly after the comments above, when discussing the way that mature reason can set bounds to the authority of testimony to which "she was at first entirely subject," Reid says: "But still, to the end of life, she finds a necessity of borrowing light from testimony, where she has none within herself, and of leaning in some degree upon the reason of others, where she is conscious of her own imbecility" (IHM VI.xxiv: 195).

So it seems that Reid holds that reliance on testimony is weaker in the mature than in young children, but nonetheless remains significant. Hence, we should probably treat the argument about the greater credulity of those with "deepest penetration" as a kind of reductio. Reid is supposing per impossibile a world in which people have no in nate tendency to believe testimony and merely believe what they are told when they can somehow test it for themselves, and then deducing from this scenario the contrary to fact conclusion that mature, highly experienced and intelligent people would be most accepting of testimony and young children the most skeptical.

In the real world, of course, the child's unquestioned trust becomes modified by the experience of betrayal, exploitation, and the mistakes of witnesses, though much of this useful experience is itself second-hand or otherwise mediated by the experience of others. The testimony-saturated nature of much that individuals treat as part of their own experiential knowledge is a striking fact that Reid could have made use of in his analysis, but somewhat surprisingly neglects. The growing awareness an individual has that witnesses betray, exploit, and mistake is founded to a considerable degree on the reliable reports of those other than the betrayers, exploiters, and mistaken. Some purely personal checking and criticism certainly goes on, but much of the critical posture toward particular testimony that maturity rightly brings arises from an amalgam of individual experience, reasoning, reliance upon witnesses, and respect for intellectual authority. Reid was certainly conscious of the mutuality of support that existed between testimony and what he calls "Reason" but he 
does not sufficiently realize the complexity of this support, nor the degree to which "Reason" itself has a social, testimonial dimension. He shows how reasoning about the context of particular reports can strengthen testimony that might otherwise be quite weak. This happens through reflection on the "character, the number, and the disinterestedness of witnesses, the impossibility of collusion, and the incredibility of their concurring in their testimony without collusion" (IHM VI.xxiv: 195). But knowledge of such things as character and disinterestedness, even impossibility of collusion, will often be available only through some reliance upon other witnesses. These will often be untested (by you) in this context.

These considerations reinforce Reid's rejection of the idea that testimony begins as a fundamental source of knowledge but is quite supplanted in later life. The capacity to use an instrument can become more sophisticated and refined by experience and one can come to appreciate its defects and limitations without ceasing to rely upon its special advantages. Reid directly compares testimony with perception, and I, and others, have followed him, though there is also a significant similarity with memory. There are analogies (and, of course, disanalogies) of varying degrees and types between testimony and each of the traditional senses with respect to epistemic role. In the Inquiry into the Human Mind, Reid's comparison occurs in the section on sight, but a comparison with hearing can also bring out some of the significance of the way our trust in testimony changes with experience and development. (Reid does not use hearing in this connection; indeed, his treatment of hearing is the most perfunctory of his accounts of the different senses.)

As children grow and develop and interact with the environment, they learn that their hearing can "play tricks" upon them. In certain circumstances, things can sound to be coming from one direction when they are coming from another; too many sounds can distort what they think they hear; they are very good at hearing and identifying some sounds and not so good at others. Furthermore, they are good listeners in certain contexts and not in others; they realize from hearing interactions with others that, with very advanced age, for instance, hearing becomes impaired in various ways, and so on. All of this tempers the epistemic reliance they put upon hearing, but none of it means that hearing is no longer a fundamental way of relating to the world around them. Indeed, many of these hearing defects, they correct by hearing itself, just as they correct some of the judgments of the other senses by the verdict of hearing ("it looks very like a blue wren, but it doesn't sound like one").

It is similar in the case of testimony. The general point is that developed understanding of the limitations of an informational modality does nothing to undermine the primitive aspects of its operation. Just as our developed understanding of the frailties inherent in memory and the various perceptual modalities does not show that we cannot have immediate (noninferential) knowledge through perception or memory, so too an increased awareness of the fallibility of testimony need not count against testimony as a frequent provider of immediate knowledge. This at least suggests strongly that, like our reliance upon perception, our basic trust in testimony needs no further justification in terms of some other source of knowledge. ${ }^{22}$

\section{JUDGMENT, TESTIMONY, AND THE}

SOCIAL OPERATIONS

In his discussions of both testimony and promising, and indeed of the other "social operations," Reid displays a robust sense of pluralism that is characteristic of much of his philosophical outlook. But although this pluralism is a strength of his outlook, it sometimes leads him astray, or at least involves him in obscurity. His comments on the relations between judgment and testimony seem to fall into this category.

The basic problem is that Reid's contrasting of the solitary and the social operations draws him unwittingly into an equally sharp contrast between things that in reality overlap. In complaining of the widespread philosophical neglect of the social operations, Reid associates this with the futile attempts "to reduce all our social affections to certain modifications of self-love"; and he also notes that where there have been "voluminous tracts" devoted to the analysis of propositions as the expressions of judgment there has been a neglect of any comparable analysis of questions, commands, and promises. This neglect extends even to the fact that what these acts express has not even been given "a name different from the operations which they express" (EIP I.viii: 70).

The neglect has been remedied in later twentieth-century philosophical discussions of what is known as speech act theory. One 
thing, however, that close attention to these matters has revealed is that some of the social operations may well express something like propositions, even though others are better understood as expressing different contents or orientations of the mind. J. L. Austin distinguished between locutionary and illocutionary acts, that is, (roughly) between saying something and further doing something communicative in saying it. Like Reid, Austin had initially been inclined to link saying and expressing propositions ("constatives") and contrast these with verbal doings ("performatives") and he also campaigned against the traditional obsession with the constatives, but he came to see that the matter was more complex. Adapting Austin, P. F. Strawson later argued that there are certain basic categories of "sayings" that enter into a variety of illocutionary acts. There are at least two such categories: propositions, having the form that $S$ is $\mathrm{P}$, and imperatives, having the form that someone $\mathrm{Z}$ is to do some act $Y$. Strawson allows that there may be more, as, for example, if the range of speech acts associated with questioning could not be accommodated under the heading of imperatives but needed a separate category of interrogatives.

There is more to be said about these issues in the philosophy of language, but, for our present purposes, the interesting point is that the contrast between these basic categories of saying does not match exactly Reid's contrast between the solitary and social operations of mind. The crucial problem for Reid is that many of the social operations clearly require the pronouncement of propositions, and so, on Reid's own account, belong with the solitary operations, since this pronouncement is an affirmation or denial expressing judgment. This seems to land Reid in contradiction. His awkward position results from not noticing, or refusing to admit, that making a judgment can serve a solitary or a social purpose. A person can be interested in just determining the truth of some matter for herself and, in thinking the matter through, come to the judgment that p. But the same person, having done so, may be interested in warning someone else that $\mathrm{p}$, or testifying to someone else that $\mathrm{p}$. Reid correctly sees that solitary judgment is different from warning or testifying and locates the difference in that between judgment as such and the social operations. But the fact seems rather to be that judgment may operate in a solitary or in a social way, since such social operations as warning or testifying clearly involve a form of judgment. My private judgment that the ice is thin becomes a component in the social act of warning that the ice is thin. Certainly, some of the social operations (such as warning that the ice is thin) involve the expression of propositions that are either true or false.

Reid's confusion here surfaces in some of his comments on testimony. He contrasts testimony and judgment in the following way:

A judge asks of a witness what he knows of such a matter to which he was an eye or ear witness. He answers, by denying or affirming something. But his answer does not express his judgment; it is his testimony. Again, I ask a man his opinion in a matter of science or of criticism. His answer is not testimony; it is the expression of his judgment. (EIP VI.i: 406-7)

There are two contrasts between testimony and judgment here. The first is an example of palpable testimony that is not the expression of judgment and the second, conversely, is an example of expressed judgment that is said not to be testimony. Let us begin with the first. On any account, what the witness says is either true or false it is propositional in form. This might predispose us to think of it as expressing the witness's judgment that things are so and so. Indeed, unless a witness so judged (on the basis of seeing or hearing) he or she would not be entitled to offer the testimony, though of course the testimony might still be given as what we sometimes call false witness. Perhaps it is this idea of false witness that leads Reid to support his claim that testimony is not judgment with the comment: "In testimony a man pledges his veracity for what he affirms; so that a false testimony is a lie: But a wrong judgment is not a lie; it is only an error" (EIP VI.i: 407). But this clearly won't do. Testimony is often false because deceitful, but it is also sometimes false because erroneous. A witness can be mislead by her perceptions, mistaken in her judgment, led astray by her memory. So Reid's first contrast is unpersuasive. His second would take us too far afield into the theory of testimony to be fully treated here. It turns on whether there can be testimony to matters of expertise, and I have argued elsewhere that there can. ${ }^{23}$ Reid is right that there are some sorts of theorizing, some matters of opinion and judgment, that are unsuited for a testimonial role, but he is wrong to rule out all results of expertise, theorizing, and judgment as so suitable. The courts, I would argue, are a good 
guide here in allowing expert testimony in certain circumstances, and our ordinary epistemic practices increasingly reflect this sort of dependence on the authority of experts.

We must conclude, then, that Reid's sharp contrast of judgment and testimony is flawed. Can we say more about the source of his confusion? In discussing the solitary operations, Reid is impressed by the fact that some mental act of judgment may express a truth without that act having any intrinsic reference to intercourse with other thinking beings. But it does not follow that judgment is not involved when our minds are employed in the social operations that do so refer. Reid may have thought otherwise because, first, some of the social operations do not in themselves involve judging that something is true or false - commands, questions, even promises are geared toward bringing it about that the world conforms to our desires and thoughts, whereas warnings and testimony are oriented, at least in part, towards our beliefs conforming to the world. For the former group we are primarily interested in satisfaction conditions, for the latter in truth conditions. This is of course rough, but it is roughly right.

Second, in the Inquiry, Reid introduces the idea of judgment with the caution that it is part of a traditional classificatory system for the intellectual powers of the mind that he does not find satisfactory. Part of this dissatisfaction is that the classification ignores the social operations, but Reid is also suspicious of other elements in the divisions of simple apprehension, judgment, and reasoning. He says, for instance, "The powers of the mind are so many, so various, and so connected and complicated in most of its operations, that there has never been any division of them proposed which is not liable to considerable objections" (EIP I.vii: 64). So it may be that the stark opposition of testimony and judgment that Reid commits himself to inherits some of the defects of the divisions about which he has already expressed skepticism. In the Essays on the Intellectual Powers, where Reid makes the comments complained of earlier, he seems less skeptical about the divisions, yet admits that both judgment and testimony involve affirmation and denial. Had he restricted himself to the idea that judgment (as he points out) may be private, involving no public affirmation or denial, whereas testimony must be expressed in a public language, he would have been on safer ground. But he immediately goes on to make the contrasts complained of above. He compares the act of judgment with the verdict of a judge in a "tribunal of justice" and speculates that the word may have been "borrowed" from the practice of tribunals. But this suggests not only that there is an intimate relation between public and private judgments, and that judgments of both kinds may be based on testimony, but also that a judge who reports his verdict to a fellow judge is thereby passing on a judgment with his testimony.

Part of the trouble here may reside in the language of acts. If we are thinking of relatively discrete acts, then we may be inclined to say that when Jones testifies that $p$, he is not then judging that $p$, since he will already have judged that $p$. Perhaps so, but this does not license us to say that his testimony cannot express his judgment, in the sense of carrying his commitment to the proposition he judged to be true. And this would leave us free to hold rightly that testimony can be erroneous. Reid seems to have been guilty in this aspect of his thought of neglecting the very thing he warned about, namely, the variety, connection, and complication of the powers of the mind and its operations.

\section{CONCLUSION}

But if Reid's rich discussion of the concept of the social operations is indeed flawed in certain ways, the imperfections are the almost inevitable accompaniments of a pioneering investigation. His fashioning of the concept of the social operations and his deployment of it in relation to deep philosophical puzzles concerning promising and testimony constitute ground-breaking theoretical achievements of a very high order. They exhibit the subtlety and balance praised by Peirce, and they also show that flash of originality that has helped make Reid an increasingly interesting and influential figure in contemporary philosophy.

NOTES

I. Peirce 1934: 296-7.

2. The example is not Hume's, but it is consonant with his discussion of the problem in THN 3.2.2: 319-20.

3. THN 3.2.5: 332 .

4. Ibid.: 333 . 
5. Ibid.: 335

6. See EAP V.vi: $664-5$.

7. The similarity is briefly noted in Lehrer 1989: 93 and 253 and is discussed in some detail in Coady I992: $54-62$. In that discussion principally concerned with epistemology, and I discuss Reid's treatment of the social operations in his Essays on the Intellectual Powers of Man, especially in EIP I.viii and VI.i. This treatment is consistent with the treatment in the Essays on the Active Powers, but the emphasis is different and supplementary. Reid's anticipation of modern speech act theory is thoroughly discussed by Schuhmann and Smith I 990: 47-62. I thank the editors of the present volume for acquainting me with this excellent article.

8. For more discussion of Reid's views in connection with testimony, see Coady I 992: esp. 54-62.

9. See Austin $1961: 223$.

Io. See EAP V.vi: 669.

I I. EAP V.vi: 669 .

12. EPM 3.I: 88

1 3. Ibid.: 89 .

14. For a more sympathetic interpretation of Hume's thought in these passages, see Kuflik 1998: 53-70. Kuflik's interesting essay argues that rough equality of power should not be treated as one of the "circumstances of justice" but he admits that these passages remain "difficult and puzzling" $(66)$

I 5. THN 3.2.I: $31 \mathrm{I}$.

16. EPM App. 3: 173

I7. Strawson 1968

I8. McGregor 1987: 483-95.

19. In Essay III, Chap. V of Essays on the Active Powers of Man, Reid in fact distinguishes two senses of resentment, sudden and deliberate, corresponding on the one hand to the instinctive hostility to any hurting and, on the other, to the more focused reaction of hostility to deliberately inflicted injuries. See EAP III.ii.v; 568-70.

20. See Putnam I 975: 2 I 5-7 I (esp. 227) and also Burge 1979: 73-I 21

21. See, for instance, Bach 1987 and Loar 1988 .

22. In this elucidation of the implications of the two principles of nature and of the way in which Reid views testimony as a fundamental source of knowledge, I have avoided a direct discussion of the exact epistemic status of the principles and of their connection with Reid's theory of common sense as expounded more fully in the Essays. There, he list various "first principles" including one concerning testimony. Like the philosophy of common sense more generally, they raise complex issues of interpretation, such as what precisely in them is to be taken as "selfevident, "whether they are to be understood as principles of truth or evidence, or whether they are principles of reliability open to indirect justifications. It would require too great a detour to canvass these matters here, but there is a good analysis of some of the central issues in Van Cleve 1999. Van Cleve also refers to a good deal of the important secondary literature around this topic.

23. See Coady r 992 : esp. 57-62. 


\section{University Library}

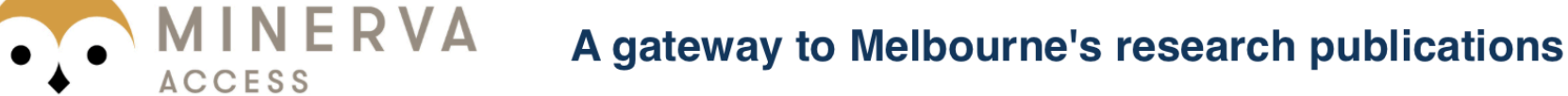

Minerva Access is the Institutional Repository of The University of Melbourne

Author/s:

COADY, CAJ

Title:

Reid and the Social Operations of Mind

Date:

2004

Citation:

COADY, C. A. J. (2004). Reid and the Social Operations of Mind. VAN WOUDENBERG, R (Ed.). CUNEO, T (Ed.). The Cambridge Companion to Thomas Reid, (1), pp.180-203. Cambridge University Press.

Persistent Link:

http://hdl.handle.net/11343/25618 